\title{
Effects of cortical spreading depression and ether following one-trial discriminated avoidance learning ${ }^{1}$
}

MANUEL BLACK, MILTON D. SUBOSKI, AND NELSON L. FREEDMAN QUEEN'S UNIVERSITY, KINGSTON, ONTARIO

Spreading depression or ether administered 5 min after shock reduced slightly the percentage of Ss avoiding the place where they were shocked. Spreading depression decreased choice latency while ether either had no effect of increased latency.

According to the consolidation theory of memory, a neural engram is not permanent immediately after learning but takes an hour or more to become established. The theory further states that while consolidation processes are still occurring they may be disrupted by various stimuli. The extent of disruption is presumably a negatively accelerated decreasing function of the learning-stimulation time interval. Cortical spreading depression, electroconvulsive shock (ECS), and certain anesthetic agents appear to interfere with consolidation processes. Apparent retrograde amnesia induced by application of these techniques has been interpreted as evidence for the consolidation theory of memory.

Those studies (e.g., Pearlman, Sharpless, \& Jarvik, 1961; Bures \& Buresova, 1963) which have used amnestic agents have in most cases used a one-trial passive avoidance conditioning paradigm in which a highly probable response is followed by a single punishing shock. However, in one-trial passive avoidance conditioning a generalized conditioned emotional response of "freezing," i.e., suppression of ongoing behavior, and passive avoidance of the punished response cannot be easily distinguished (Spevack \& Suboski, 1967). If an animal fails to make a response previously followed by shock, he may have learned not to make that particular response or it may be indicative of a general suppression of behavior. Furthermore, Chorover \& Schiller (1966) have suggested the possibility that ECS can alleviate conditioned suppression effects, presumably by removal of the locomotor inhibition of the CER without affecting memory processes.

One experimental result which suggests that spreading depression affects conditioned suppression rather than retention of a conditioned passive avoidance response was reported by Kupferman (1965). He trained rats to discriminate between horizontal and vertical stripes with food as reinforcement. Immediately after learning the problem, the rats were bilaterally depressed with $25 \% \mathrm{KCl}$ and tested $24 \mathrm{~h}$ later for retention. No impairment of learning was observed. One possible reason for the fallure of spreading depression to produce retention deficits was the use of positive reinforcement so that conditioned suppression did not develop.
In one-trial discriminated avoidance conditioning (Beaumaster \& Suboski, 1967), separation of conditioned suppression and avoidance would be possible. If two responses are available, one is punished and the animal then makes the unpunished response, avoidance would be indicated. If the animal fails to make either response or shows increased latency of responding, conditioned suppression would be indicated.

Method

Subjects. The Ss were 50 male hooded rats weighing 250-300 $\mathrm{g}$.

Apparatus. The apparatus consisted of an open field in the shape of a right triangle with small chambers cutting off the acute angles. The small chambers had inside dimensions of $6 \times 5 \times 6 \mathrm{in}$. high. One of the chambers was painted white outside and had a 3 in. circular opening from the larger chamber. The other was black with a 3 in. square opening. The floors of both chambers consisted of steel grids. A $150 \mathrm{~W}$ flood lamp was suspended 12 in. above the center of the large chamber. A Grason-Stadler shock scrambler was set to deliver a $5 \mathrm{~mA}$ shock to the grid floors.

Procedure. Each $\mathrm{S}$ was placed behind a Plexiglas panel held across the right angle of the large chamber. After $10 \mathrm{sec}$ the panel was removed and 2 min after $S$ entered one of the small chambers he was taken from the apparatus. Alternated free and forced single dally trials (two of each) were given, with the entrance to the previously chosen chamber blocked on forced trials. After the last forced trial all animals were subjected to the same surgical procedure. The skull was exposed and two $3 \mathrm{~mm}$ holes were trephined $1 \mathrm{~mm}$ behind the bregma on either side of the saggital sinus. Cannulae approximately $1 \mathrm{~cm}$ long, the flared end over the hole, were secured with dental cement and small screws. After surgery the cannulae were flushed and filled with Ringer's solution. One day was allowed for recovery before further treatments were initiated.

The Ss were randomly assigned to four groups. Group No Shock Saline and Group No Shock SD (N=10 each) assessed the effects of saline and $\mathrm{KCl}$ alone on

Table 1. Percentage reversals, mean latency, and mean number of boli left in the open field for Experiment 1.

Shock-SD Shock-saline NoShock-SD NoShock-saline

\begin{tabular}{lrrrr}
\hline $\begin{array}{l}\text { \% reversals } \\
\text { mean latency } \\
\text { (sec) }\end{array}$ & 256.3 & 80.0 & 40.0 & 20.0 \\
boli & 2.5 & 410.3 & 5.1 & 5.4 \\
\hline
\end{tabular}


Table 2. Percentage reversals, mean latency, and mean number of boluses left in the open field for Experiment 2.

\begin{tabular}{lrrrr} 
& $\begin{array}{c}\text { Shock- } \\
\text { ether }\end{array}$ & $\begin{array}{c}\text { Shock- } \\
\text { no ether }\end{array}$ & $\begin{array}{c}\text { No shock- } \\
\text { ether }\end{array}$ & $\begin{array}{c}\text { No shock- } \\
\text { no ether }\end{array}$ \\
\hline \% reversals & 73.3 & 80.0 & 33.3 & 26.6 \\
mean latency (sec) & 543.3 & 597.9 & 4.3 & 36.5 \\
boluses & 4.1 & 3.9 & .1 & .3 \\
\hline
\end{tabular}

performance. During treatment each $\mathrm{S}$ was placed in the apparatus and the panel was removed after $10 \mathrm{sec}$. After entering one of the small chambers, $S$ was removed, and $5 \mathrm{~min}$ later both cannulae were thoroughly flushed with either saline or a $33 \% \mathrm{KCl}$ solution. The Ss' cannulae were flushed with saline $45 \mathrm{~min}$ later.

For the two shock treatment groups, Shock Saline and Shock SD $(\mathrm{N}=15 \mathrm{each})$, the grids of both chambers were electrified so that $S$ received a $5 \mathrm{~mA}$ shock to the feet as he entered either of the two chambers. If $S$ entered the chamber in spite of the shock, it was turned off and a series of brief shocks were administered until $\mathrm{S}$ left the chamber. Five min after entering the chamber, S's cannulae were flushed with either saline or a $33 \% \mathrm{KCl}$ solution. The S's cannulae were flushed with saline $45 \mathrm{~min}$ later. The following day all Ss were given a free choice in the apparatus. The large panel was removed after $30 \mathrm{sec}$ and the choice latency was measured from the release time until $\mathrm{S}$ had all four paws inside one of the small chambers. A bolus count was also taken for each $S$.

\section{Results and Discussion}

Table 1 shows percentage reversals, mean latencies with $1000 \mathrm{sec}$ as the maximum latency, and mean bolus counts for all four groups. As may be seen from the table, $80 \%$, or 12 of the Shock-Saline rats reversed on posttreatment test, whereas only $53 \%$, or eight of the Shock-SD Ss reversed. Fisher's exact test Indicated that the difference was not significant. The effect of shock on discrimination was analyzed by combining both shock groups (S-S and S-SD) and comparing them to the no-shock groups (NS-S and NS-SD). Of the shocked animals, 66\% reversed from the chamber in which they had been shocked, while only $30 \%$ of the unshocked animals reversed. The binomial approximation to the normal curve indicated a significant difference between these groups $(z=2.29, p<.05)$.

Table 1 shows that the Shock-SD group had shorter latencies than the Shock-Saline group $(t=2.68, \mathrm{df}=28$, $p<.02)$. Mean Shock-SD group latency for the Ss that reversed was $468.1 \mathrm{sec}$ and $246.4 \mathrm{sec}$ for those that did not reverse. The difference between the means, however, was not significant $(t=.67)$. No comparable difference appeared in the Shock-Saline group. The effect of shock, as shown in Table 1, was to greatly increase latency over the unshocked groups. The difference in mean number of boli between Shock-SD and Shock-Saline was not significant $(t=1.78, d f=28, p<$ .1). Table 1 also shows that shock greatly increased
Table 3. Percentage reversals, mean latency, and mean number of boluses left in the open field for Experiment 3.

\begin{tabular}{lcc} 
& Shock-ether & Shock-no ether \\
\hline \% reversals & 66.3 & 86.6 \\
mean latency (sec) & 667.5 & 252.3 \\
boluses & 4.2 & 3.4 \\
\hline
\end{tabular}

defecation as compared to the unshocked groups.

Although the present results favor consolidation theory, they are by no means unequivocal. Further study is needed; specifically, different shock-spreading depression intervals are needed to see if a graded discrimination function would result.

\section{Experiments 2 and 3}

Experiment 2 used the same design as Experiment 1 except that $\mathrm{Ss}$ were either placed in a plastic bottle contalning ether soaked gauze pads or a similar container without ether for $1 \mathrm{~min}$ beginning 5 min after training. The results, shown in Table 2, indicate that other than the expected differences between shocked and unshocked groups, the treatments appear to have had little effect.

Experiment 3 replicated the shocked groups of Experiment 2, but with the duration of ether exposure increased to $100 \mathrm{sec}$. The results are shown in Table 3. It can be noted that while ether exposure had only a slight effect on reversals and defecation, ether sharply increased latency $(t=4.13, d f=28, p<.001)$, a result opposite to that expected from an effect on memory. Proper evaluation of the two ether experiments is not possible at the present time. However, recent reports in the literature have indicated that ether temperature is a critical factor in producing apparent retrograde amnesia, with higher temperatures producing greater effects. The present experiments were conducted at room temperature.

\section{References}

BEAUMASTER, E., \& SUBOSKI, M. D. A one-trial discriminated avoidance conditioning technique, read at Canad. Psychol. Assoc. meet., Ottawa, May, 1967.

BURES, J., \& BURESOVA, O. Cortical spreading depression as a memory disturbing factor. J. comp. physiol. Psychol, 1962, 55, 1082-1084.

CHOROVER, S. L., \& SCHILLER, P. H. Reexamination of prolonged retrograde amnesia in one-trial learning. J. comp. physiol Psychol, $1966,61,34-41$.

KUPFERMAN, I. Failure of spreading depression to produce retrograde amnesia. Psychon. Sci., 1965, 3, 43-44.

PEARLMAN, C. A., SHARPLESS, S. K., \& JARVIK, M. E. Retrograde aminesia produced by anesthetic and convulsant agents. $J$. comp. physiol. Psychol., 1961, 54, 109-112.

SPEVACK, A. A., \& SUBOSKI, M. D. A confounding of conditioned suppression in passive avoidance: ECS effects. Psychon. Sci, 1967, 9, 23-24.

\section{Note}

1. These data were reported at the Canadian Psychological Association meeting, Ottawa, May, 1967. This research was supported by Grant No. 161 from the Ontario Mental Health Foundation. 